\title{
Formação de professores e educação em direitos humanos e cidadania: dos conceitos às ações
}

\author{
José Sérgio Carvalho \\ Universidade de São Paulo \\ Adriana Pereira Sesti \\ Julia Pinheiro Andrade \\ Luciano da Silva Santos \\ Wellington Tibério \\ Membros do Projeto Direitos Humanos nas Escolas
}

\section{Resumo}

Este artigo relata a experiência do Projeto Direitos Humanos nas Escolas na elaboração e realização de um curso de formação de professores voltado para a difusão dos ideais e valores dos direitos humanos, da democracia e da cidadania como eixos norteadores de toda e qualquer prática escolar e não apenas de discursos pedagógicos. Cabe destacar que se trata de um desafio de grande envergadura dada as características históricas tanto da escola brasileira quanto da nossa sociedade em sentido amplo. Considerando tal desafio, apresenta de forma sintética os princípios, atividades e reflexões resultantes das experiências mais significativas dos três primeiros anos de trabalho desse projeto com escolas da rede estadual e municipal nos municípios de Osasco e São Paulo.

Entre outras coisas, este artigo expõe as diferentes formas que o referido curso assumiu dada a dificuldade da criação de um formato de atividades capazes de tornar as práticas do cotidiano escolar um objeto de reflexão para os envolvidos diretamente com a ação educativa, assim como para as instituições escolares como um todo, e aponta importantes características que essa proposta de formação continuada de professores gerou na busca da elucidação dos desafios que a atual escola brasileira deve enfrentar na realização de sua função pública.

\section{Palavras-chave}

Valores públicos - Formação continuada - Práticas escolares Instituição escolar.

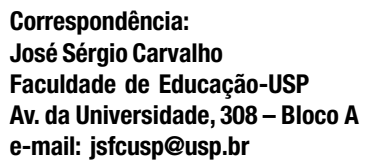




\title{
Teacher education and the education in human rights and citizenship: from concepts to actions
}

\author{
José Sérgio Carvalho \\ Universidade de São Paulo \\ Adriana Pereira Sesti \\ Julia Pinheiro Andrade \\ Luciano da Silva Santos \\ Wellington Tibério \\ Membros do Projeto Direitos Humanos nas Escolas.
}

\begin{abstract}
This article reports on the experiences of the Human Rights in Schools Project in the creation and conduction of a teacher education course aiming at the dissemination of the ideals and values of human rights, democracy and citizenship as guiding principles for each and every school practice, and not just for pedagogical discourses. It must be said that such objective constitutes a great challenge, given the historical features of the Brazilian school and of the Brazilian society at large. Against the backdrop of that challenge, the text summarizes the principles, activities, and reflections resulting from the most significant experiences of the first three years of work of this project in schools belonging to the state and municipal networks in the cities of São Paulo and Osasco.

Among other things, this article presents the different forms assumed by the above-mentioned course given the difficulty in shaping activities capable of turning school's everyday practices into an object of reflection for those directly involved in the act of educating, as well as for the school institution as a whole. It also points out important features engendered by this teacher continuing education proposal in its search for answers to the challenges currently faced by the Brazilian school in fulfilling its public role.
\end{abstract}

\section{Keywords}

Public values - Continuing education - School practices - School institution.

\footnotetext{
Contact:

José Sérgio Carvalho

Faculdade de Educação-USP

Av. da Universidade, 308-Bloco A

e-mail: jsfcusp@usp.br
} 
Parece ser cada vez mais consensual ou pelo menos cada vez mais amplamente proclamado - que o ideal maior da ação educativa escolar deve ser a preparação para o exercício da cidadania e a formação de uma conduta ética e solidária. Nos discursos pedagógicos há uma ênfase recorrente na necessidade de iniciação de jovens no campo de práticas e conhecimentos relativos aos valores públicos vinculados à democracia e aos direitos humanos. É o que encontramos, por exemplo, em documentos pedagógicos importantes, como as $\mathrm{Di}$ retrizes e os Parâmetros Curriculares Nacionais (1998). É necessário reconhecer, contudo, que a aceitação dessa meta como principal diretriz educacional tem sido mais retórica do que prática. A escola brasileira, em que pese a ênfase discursiva em relação à proclamação dos ideais da cidadania e da igualdade, tem sido marcada por práticas e concepções que valorizam seu impacto mais por eventuais benefícios privados - em geral de natureza econômica - do que por seu potencial social e público.

Inúmeros são os desafios para que se supere essa visão da escolarização em favor de ideais ligados à noção de uma formação voltada para o bem comum. Qualquer transformação que diga respeito a uma mudança dessa magnitude exigirá, inexoravelmente, uma série de medidas complementares. Dentre elas uma que nos interessa diretamente: a formação de professores, não só em seus estágios iniciais, ao longo das licenciaturas, mas também na formação continuada que se volta para os professores já em serviço.

Nesse âmbito, é preciso reconhecer que a maior parte das iniciativas oficiais tem se centrado na idéia de um aperfeiçoamento individual do docente, sem lograr inseri-lo no contexto institucional em que concretamente trabalha, ou seja, na escola (Azanha, 1987). Assim, sobretudo no que diz respeito a programas de formação contínua de professores, tem sido bastante freqüente o descolamento entre a reflexão sobre os conceitos difundidos e a consideração das práticas correntes nas unidades esco- lares. Normalmente realizados fora da escola, os programas de formação contínua se propõem a "reciclar" o repertório dos discursos dos educadores em "temáticas e metodologias inovadoras" e, deste modo, simplificam a questão da educação para a democracia e os direitos humanos, tornando-a um problema de divulgação de idéias a cargo de um indivíduo isolado de seus pares e da proposta pedagógica de sua escola.

Dentre inúmeros equívocos, vale ressaltar, em primeiro lugar, o fato de que a educação de valores fundamentais à vida pública não pode consistir meramente na transmissão de informações, tais como o conteúdo da Declaração dos Direitos do Homem ou os princípios da Constituição da República. Por certo, a posse dessas informações pode desempenhar um papel fundamental na elaboração de conceitos e práticas vinculados à educação para cidadania. Mas sua mera tematização não garante uma ação educativa vinculada a esses valores. ${ }^{1}$ Tampouco leva inexoravelmente à adesão, por parte dos alunos, de um modo de vida neles fundado. Pelo contrário, não é raro que a retórica democrática à qual se expõem os alunos seja acompanhada de atos de discriminação, exclusão, enfim de toda a sorte de violações concretas de direitos. Assim, não raramente a escola acaba por contribuir para a manutenção de um enorme e indesejável fosso entre a proclamação de direitos e sua efetivação.

Em se tratando de educação, de modo geral, antes de discursos e informações, são as ações o que importa considerar. Com mais razão, portanto, o sentido de uma educação comprometida com os ideais e valores da cidadania, da democracia e dos direitos humanos se expressa menos nas informações e nos discursos transmitidos do que nos princípios de condutas que regem, no cotidiano escolar, as ações educativas de uma instituição.

1. Podemos vislumbrar mais claramente essa questão se atentarmos para a diferença implicada na idéia de "ensinar que a democracia é um regime (...)" e "(...) ensinar a viver democraticamente" [grifos nossos]. A segunda idéia pode até pressupor a primeira, mas nela não se esgota. A esse respeito veja-se Scheffler, 1978. 
Visando lidar com pelo menos alguns desses problemas, o Projeto Direitos Humanos e Cidadania nas Escolas vem desenvolvendo, há cerca de três anos, uma proposta de política pública em aperfeiçoamento de práticas docentes a partir de algumas inovações fundamentais. Em primeiro lugar, seu processo de elaboração se dá em diálogo com instituições escolares públicas, desenvolvendo projetos conjuntos no interior das escolas, considerando-as parceiras efetivas de todo trabalho de concepção e execução de atividades. De acordo com esse projeto, entende-se que cabe à universidade, bem como aos órgãos governamentais, um esforço elucidativo conjunto (universidade, órgãos governamentais e instituições escolares) que torne patente a natureza dos desafios que a função pública da escola hoje enfrenta e não a apresentação de "visões iluminadas" acerca dos dilemas práticos das instituições.

Considera-se, portanto, que somente uma comunidade escolar, na concretude de seus desafios cotidianos, poderá estabelecer de forma significativa seus parâmetros de ação ética, por meio de uma discussão constante dos princípios gerais de nossa cultura e dos compromissos históricos de nossas instituições de ensino. Nesse sentido, busca-se antes a adesão a esses princípios fundantes da educação pública do que a propagação de ações uniformes por meio de sugestões padronizadas como "métodos" de ensino. Por essa razão o foco do trabalho encontra-se na formação de uma equipe de professores que, deixando de ser meros reprodutores individuais de receituários pedagógicos, venham a ser seus autores efetivos.

A preocupação temática do Projeto, portanto, não é meramente técnica, mas refere-se à difusão e à consolidação de um modo de se conceber e fazer educação. Sua concepção de educação sustenta que os ideais e valores dos direitos humanos, da democracia e da cidadania não devem se limitar a ser temas geradores de aula, mas constituir-se em eixos norteadores de toda prática escolar e princípios inspiradores de ações educativas e não só de discursos pedagógicos.
Assim, o propósito do projeto é a apresentação, discussão e o cultivo de um núcleo de princípios éticos públicos (Vieira, 2002) a partir dos quais cada escola, na autonomia de sua proposta de ação pedagógica, procure caminhos próprios de operacionalização. A unidade, então, deverá resultar não numa padronização didática, temática ou metodológica, mas na comunhão em torno de certos princípios e objetivos.

Este artigo pretende descrever a experiência do projeto na área de formação contínua de professores de escolas públicas desde sua primeira formulação, elaborada a partir do trabalho realizado em duas escolas estaduais de São Paulo, até sua versão mais acabada, desenvolvida junto ao Núcleo de Ação Educativa n. 10 da cidade de São Paulo, órgão municipal de educação da região de São Miguel Paulista. ${ }^{2}$ Procuramos narrar o processo de pesquisa inicial e implementação de cursos considerando os desafios da reflexão sobre a temática do trabalho e da criação de um formato de atividades capaz de tornar as práticas do cotidiano escolar um objeto de reflexão. Concomitantemente, procuramos explicitar as inovações propostas para a formação docente em serviço.

0 desafio veio e vem sendo grande e o percurso a seguir evidencia, sinteticamente, três momentos diferentes do trabalho do projeto entre 2001 e 2003, cada qual correspondente às três diferentes versões que um tal curso de aperfeiçoamento docente pôde assumir.

\section{A história do curso em direitos humanos e educação para democracia}

0 Projeto Direitos Humanos e Cidadania nas Escolas surge, em 2000, do convênio de cooperação firmado entre a Cátedra USP/Unesco de Educação para a Paz, Direitos Humanos,

2. Quando o trabalho foi iniciado com as escolas da região de São Miguel Paulista, em parceria com a subdivisão da Secretaria Municipal de Educação responsável por aquela região, essa era identificada como Núcleo de Ação Educativa n. 10; porém atualmente ela passou a se chamar Coordenadoria de Educação da Subprefeitura de São Miguel Paulista. 
Democracia e Tolerância e a Faculdade de Educação da USP como uma proposta de formação de professores de acordo com esta temática. Já em sua formulação inicial, o projeto propunha que tais ideais não fossem considerados só mediante a presença da temática nas escolas, mas propiciassem a discussão e a reflexão sobre os problemas neles envolvidos, bem como a reflexão sobre possíveis práticas educativas e políticas públicas de educação capazes de promover tais valores como compromissos que se traduzam em ações educacionais das instituições escolares.

Assim, ao propor-se a efetivar uma nova forma de relação entre universidade e escola, em 2001 o projeto passou a integrar a área de pesquisa em políticas públicas da Fapesp, empenhando-se na viabilização de novas práticas em aperfeiçoamento docente em duas escolas estaduais tomadas como campo de experimentação. ${ }^{3}$ A ação preliminar foi a realização de uma série de entrevistas visando obter um primeiro quadro geral das concepções e discursos dos professores acerca do papel da escola na formação geral de seus alunos e, mais especificamente, suas visões sobre os desafios e as possibilidades de um trabalho educativo institucional voltado para a formação e o cultivo de valores e hábitos identificados com os direitos humanos e com o exercício da cidadania.

Em relação ao entendimento sobre qual seria o papel desempenhado hoje pela escola em nossa sociedade, foi pedido aos professores que escolhessem - e justificassem entre as seguintes alternativas, qual melhor definia os objetivos do ensino básico: enfrentar um mercado de trabalho futuro, a participação na vida em sociedade, enfrentar o vestibular, impulsionar o desenvolvimento econômico do país e familiarizar os alunos com as heranças culturais de um povo. Verificou-se que, para a maior parte dos professores entrevistados nas duas escolas estaduais, a função do ensino escolar relacionava-se às alternativas ligadas à formação para o exercício da cidadania, apresentando em suas justificativas uma ampla utilização dos discursos pedagógicos oficiais, os quais, portanto, conheciam bem. Assim, aparentemente, a coordenação do projeto não necessitaria realizar um trabalho de sensibilização dos professores à temática da educação em direitos humanos e cidadania, uma vez que os dados dessa pesquisa preliminar permitiam a interpretação de uma oportuna convergência entre os objetivos do projeto e a expectativa dos professores quanto aos resultados do processo educativo.

No entanto, quando confrontada com as condutas e ações educativas no cotidiano escolar e com os discursos informais, tal convergência se mostrou bastante frágil. Nesse caso, como em tantos outros análogos, professar um ideal comum pode não representar muito mais do que recorrer a uma mesma expressão: “formar o cidadão". Assim, mais do que comungar práticas pedagógicas ou mesmo concepções de educação, a recorrência ao ideal de "formação para a cidadania" parecia funcionar como um recurso retórico de aceitação imediata, uma resposta "correta" e "oficial" ao questionário.

A convivência no cotidiano escolar mostrou-nos tanto a fragilidade da adesão aos ideais como a freqüente presença de condutas absolutamente contraditórias com os valores públicos da educação. Para citar apenas dois exemplos, um de cada unidade escolar, mencionamos dois casos extremos: em uma escola, um professor associava o ideal de cidadania a falas saudosas "da ordem dos bons tempos da ditadura militar"; em outra, professores, coordenadores e diretora, "tomados pelo medo" da violência em meio escolar e sem conseguir trabalhar sua responsabilidade institucional diante dessa complexa questão, vinham procurando ora a publicidade da mídia (canais de TV com programas sensacionalistas), ora a polícia, para lidar com problemas de indisciplina de seus assim chamados "alunos-problema". Desse modo, logo se tornou

3. As escolas escolhidas pertenciam à Diretoria Regional de 0sasco, uma delas localizada no centro e outra na periferia desta cidade. 
evidente que a ênfase do trabalho deveria partir não da consideração da pertinência dos ideais de educação vinculados aos princípios públicos, mas de sua consideração de acordo com uma reflexão sobre os meios pelos quais uma escola - com uma tradição de seletividade e hierarquização, como tem sido a brasileira pode desenvolver práticas pedagógicas que exprimam em suas ações os compromissos públicos professados.

Demonstrava-se, assim, a fragilidade e a banalização de conceitos essenciais ao ideal da educação pública quando resultantes meramente do empenho pela tematização discursiva de seus valores fundamentais em projetos pedagógicos ou de sua incorporação automática ao programa das diversas disciplinas, tal como um tema transversal de parâmetro curricular - ambas modalidades de difusão promovidas há pelo menos uma década, pelo próprio Estado. Por desejáveis que sejam, tais modalidades não atingem o cerne da questão da educação em valores: torná-la o centro de uma reflexão sistemática, coletiva e cotidiana sobre as práticas de ação educativa de todo e qualquer agente institucional de uma instituição escolar e, fundamentalmente, da equipe de docentes que a integram.

Diferentemente de considerar o mero ensino de informações, mas também, para além do difícil e demorado ensino de ações e habilidades, trata-se de considerar a possibilidade do ensino de princípios de conduta fundados em valores públicos essenciais, o que supõe, por parte dos agentes de ensino, uma ação ética e coletiva em relação a esses princípios ou seja, um tipo de formação contínua que permita a construção da coerência institucional do coletivo escolar com relação a valores vinculados à democracia, à cidadania e aos direitos humanos (Carvalho, 2002).

Desse modo, em primeiro lugar, mostrava-se necessário trabalhar o entendimento desse tipo de situação, um disparate entre princípios públicos e condutas cotidianas, como um problema grave e de ordem coletiva. Ademais, como um agravante para o enfrentamento des- se tipo de questão encontrávamos naquelas escolas, reiterada e atualizada, uma visão amplamente difundida na cultura escolar brasileira, segundo a qual uma boa escola consiste na reunião, como simples soma de indivíduos, de professores competentes e bem formados. 0 grupo de professores de cada uma das duas unidades em que atuava o projeto não se percebia responsável pelas práticas institucionais, tampouco desenvolviam trocas de experiências conjuntas que permitissem o enriquecimento de conceitos provenientes de suas diversas formações e de práticas adquiridas ao longo de seu exercício profissional. Pelo contrário, não encontrando um modo efetivo de desenvolver essa prática de formação contínua, mantinham o vezo de tornar os horários de trabalho coletivo em sessões absolutamente improdutivas de lamentações individuais dirigidas à coordenação pedagógica, alternando monólogos, sem claro proveito para a prática escolar coletiva. ${ }^{4}$

Por conseguinte a organização de espaços de reflexão coletivo sobre a natureza dos problemas envolvidos em um conceito de educação fundado nos ideais dos direitos humanos e da democracia ainda deveria lidar com este desafio: romper com a visão de que um bom quadro docente, na escola, é aquele constituído pelo conjunto de "preceptores" isolados (São Paulo, 2000), cujos êxitos são conquistas individuais e cujo trabalho pode se dar de forma individualizada. 0 passo seguinte, portanto, foi o desenvolvimento de um diagnóstico coletivo dos principais problemas a serem enfrentados, em ambas as escolas, para a consecução do ideal educativo já identificado em seus discursos. Desse processo resultou a primeira forma do curso de formação contínua desenvolvida pelo projeto, associando, de um lado, a elaboração de oficinas em direitos humanos

\footnotetext{
4. Não buscamos com isso negar a necessária elaboração dos tantos problemas e situações adversas com as quais os professores se deparam cotidianamente, no entanto desde que isto não se dê em detrimento de um processo de construção de soluções e ações coletivas, o que passa necessariamente pela formulação de um projeto de escola que busque ressignificar a relação dos alunos com a instituição escolar como um todo (aulas, conteúdos, professores, uso público do espaço escolar, relações de poder, etc.).
} 
organizadas por licenciandos da Feusp nas duas unidades escolares, e, de outro lado, a realização de palestras e debates para os professores sobre os temas por eles mesmos formulados, os quais foram realizados na Feusp.

A formulação desses "temas-diagnósticos" surgiu durante o trabalho de pesquisa nas escolas. Nas discussões nos Horários de Trabalho Pedagógico Coletivo (HTPC) se configurou a necessidade de reflexão sobre as principais questões que, segundo os professores, representavam impedimentos para uma ação educativa escolar vinculada aos ideais dos direitos humanos e do exercício da cidadania, a saber: o papel da mídia, notadamente a televisão, na formação de valores e da cultura jovem; a relação entre escola e família, o papel da educação familiar e os conflitos de geração; os problemas relacionados com as diversas formas de violência presentes em meio escolar.

A consideração dessas questões enquanto temas ao mesmo tempo gerados e geradores de um diagnóstico coletivo acerca das dificuldades das ações educativas em ambas as escolas resultou na elaboração de um curso de extensão universitária em direitos humanos e cidadania oferecido pelo Projeto na Feusp. Em uma primeira etapa, em 2001, foram realizadas palestras apenas para os docentes das duas escolas estaduais participantes do projeto cujos temas foram: mídia e educação; e família e escola. ${ }^{5}$

Em que pese a excepcional qualidade das discussões e a repercussão positiva desse evento junto aos professores, as avaliações do grupo de coordenadores e monitores apontaram certos problemas que motivaram a busca por novas formas de ação visando à formação continuada dos docentes envolvidos no projeto. A principal crítica foi a de que as palestras, realizadas no período noturno, contavam com um tempo exíguo para debates ou mesmo planejamento de ações por parte dos professores. Em nossa concepção inicial esses debates aconteceriam nos HTPCs das escolas. No entanto, este tipo de procedimento acabou sendo pre- judicado pelo fato de que nem todos os professores presentes nessas reuniões tiveram a oportunidade de assistir as palestras. Mesmo nas ocasiões em que recorremos ao vídeo das palestras filmadas, o impacto da discussão foi bem menor do que esperávamos.

\section{Das primeiras palestras à elaboração da primeira versão do curso}

Em face desse problema decidimos que, para a etapa seguinte do trabalho (a montagem de um curso propriamente dito), seria conveniente propor a criação de grupos de trabalho imediatamente depois das palestras. Dessa forma, os professores das escolas envolvidas teriam ocasião de debater os assuntos discutidos à luz de suas experiências e dificuldades cotidianas, inclusive propondo encaminhamentos práticos. Essa solução, contudo, trouxe uma nova dificuldade: o tempo de permanência desses professores na Feusp. Para saná-la, decidimos propor a organização de um curso de “extensão cultural”, oferecido pela Feusp aos professores dessas escolas - com as vagas remanescentes abertas prioritariamente a outras escolas públicas ligadas de alguma forma à Feusp ou que aspiravam integrar este ou outro projeto da faculdade -, no qual pudéssemos alternar momentos de discussão teórica com grupos de trabalho e oficinas pedagógicas.

Desse modo, evidenciava-se a necessidade de aprimorar uma forma coletiva não apenas de contato com temas e conceitos fundamentais, mas de elaboração conceitual por meio de trocas de experiências entre equipes de professores de diferentes unidades escolares. Isto porque o contato com outras escolas públicas, para além daquelas duas unidades estaduais, demonstrava a recorrência de temas e discursos comuns, normalmente já considerados em cursos de formação contínua de professores. Porém, sua sim-

5. As palestras foram proferidas, respectivamente, pelos professores Eugênio Bucci (Faculdade de Jornalismo da Cásper Líbero), Amaury César Moraes, Lisandre Castello Branco e Flávia Schiling (todos da Feusp). 
ples tematização em palestras e debates, como apontamos, permitia aperfeiçoar tão somente discursos, não os confrontando com práticas e exemplos de ações educativas.

Por essa razão, no ano seguinte, em 2002, o projeto do curso de extensão universitária se ampliou para mais escolas da rede pública e foram firmadas duas inovações essenciais: 1) a inscrição deveria se dar não por professores individualmente, mas por equipes de pelo menos cinco docentes; e 2) em seguida às palestras, passamos a organizar grupos de trabalho para aprofundar o entendimento sobre os conceitos fundamentais abordados mediante duas formas de trabalho: reflexão sobre os textos dos palestrantes e a elaboração de possiveis ações exemplares, a serem praticadas ou propostas pela equipe de professores em suas unidades escolares.

0 curso foi estruturado em três módulos temáticos, cada um dos quais trabalhados entre dois e quatro encontros na Feusp, de modo a permitir a realização de: a) palestras e debates; b) troca de experiências e elaboração conceitual dos textos de palestrantes compilados em uma apostila; e c) consideração de práticas educativas e formulação de ações nas unidades escolares participantes. 0 primeiro módulo, desenvolvido em quatro encontros, concentrou-se na temática Direitos Humanos, Cidadania e Educação; o segundo, em dois encontros, nas relações entre Cultura Jovem e Currículo Escolar; e o terceiro, novamente em quatro encontros, no tema da Violência Social e a Instituição Escolar. Na abertura de cada módulo organizamos uma palestra com especialistas nos temas, sempre procurando apresentar uma visão geral do problema para, em seguida, aproximá-lo mais das práticas e valores escolares por meio de discussões em subgrupos, que reuniam professores de uma mesma escola e monitores dos projetos.

Os trabalhos se desenvolveram ao longo de três meses e meio. No total recebemos, nessa primeira versão do curso, 180 professores, diretores e coordenadores pedagógicos de mais de vinte escolas públicas de São Paulo, Diadema e Guarulhos. Nossa intenção inicial era abrir 120 vagas, mas a procura foi tão acima de nossas expectativas que decidimos ampliar esse número. Ainda assim, diversas escolas não puderam ser atendidas nessa ocasião. A avaliação do curso foi extremamente positiva e diversos convites para a ampliação da experiência começaram a ser feitos ao Projeto.

\section{Curso em parceria com o NAE 10 - Diretores e Supervisores}

Por ocasião da realização dessa primeira versão do curso recebemos um convite do Núcleo de Ação Educativa n. 10 (NAE 10) para estruturar um curso semelhante, mas voltado exclusivamente para as escolas municipais que estavam sob a competência desse órgão administrativo e pedagógico (que abarcava a região de São Miguel Paulista, Itaim Paulista e Ermelino Matarazzo, no extremo leste de São Paulo). Nesse novo contexto, o projeto de formação contínua não somente aprofundaria a possibilidade de replicação do curso, como viria a apresentar uma novidade: tornar-se um curso de difusão cultural em direitos humanos e cidadania reconhecido pela Universidade de São Paulo, não apenas fora de seu campus, mas iniciando sua penetração no interior das escolas públicas.

Desde o início da formulação dessa nova modalidade do curso, foi constituída uma verdadeira parceria entre o Projeto Direitos Humanos nas Escolas e o NAE 10, cuja equipe não se limitou a viabilizar inscrições e atividades, tornandose co-responsável por toda a elaboração temática e operacional do trabalho. Assim, ao longo de reuniões semanais conjuntas, as duas equipes, a do Projeto e a do NAE 10, discutiram tanto as temáticas que seriam abordadas e as estratégias de trabalho a serem adotadas quanto o material a ser entregue aos participantes.

Por orientação da coordenação do NAE 10, essa versão do curso foi destinada não a equipes de professores das escolas, mas a diretores e supervisores de ensino da região. Tal 
escolha se deu pelo fato de que, devido às inovações no propósito e na abordagem do projeto de formação contínua de professores, era preciso garantir uma sensibilização dessas autoridades escolares para a natureza da discussão proposta. Sendo os diretores e supervisores os mediadores para o convite aos professores em uma região bastante carente de iniciativas semelhantes à desse projeto, a escolha procurava evitar que a posterior decisão de participação por parte das escolas se tornasse burocrática ou arbitrária, condições recorrentes na área de aperfeiçoamento docente. Por essa razão, também o formato do curso foi adaptado ao público escolhido: uma palestra semanal, de cerca de duas horas, complementada por discussões em grupos formados por profissionais das mesmas microrregiões administrativas do NAE, nos quais foram feitas discussões conceituais a partir de textos e seu confronto perante o levantamento de práticas e ações educativas partilhadas coletivamente.

Ao longo de um mês e meio de trabalho, foram trabalhados os seguintes temas: 0 Conceito de Cidadania e o Desenvolvimento Histórico dos Direitos Humanos; Direitos Humanos nas Escolas: Podem a Ética e a Cidadania ser Ensinadas?; A Constituição Brasileira e os Direitos Humanos; Redes como Recurso de Redução da Violência Escolar; Conflitos nas Relações Escolares: Diagnóstico e Encaminhamentos; Avaliação e Democratização das Oportunidades; Mídia, Educação e Cidadania. ${ }^{6}$ Visando a ampliação do trabalho desenvolvido, foi possivel viabilizar por meio do projeto a filmagem de todas as palestras, por profissionais especializados, a fim de futuramente dispor de videodocumentários sobre os temas. Esses vídeos integrarão o material didático para eventuais cursos futuros.

\section{Versão final do Curso junto ao NAE 10 - Professores}

Paralelamente ao desenvolvimento do curso para diretores, as equipes do Projeto e da Supervisão do NAE 10 continuaram seus encon- tros semanais visando a elaboração do curso aos professores da região, para o ano seguinte. No último dia de encontro, apresentamos aos diretores a proposta de um curso anual, voltado a professores e coordenadores pedagógicos das escolas, com a mesma temática, mas novamente com inovações no formato, nesse caso visando uma maior aproximação da realidade escolar por meio de um acompanhamento sistemático das instituições envolvidas.

Por essa razão, a programação se modificou e se alargou em comparação com os cursos anteriores, prevendo quatro encontros mensais de natureza distinta: um primeiro, com uma tarde de trabalho para as palestras; um segundo, coordenado pelos monitores do curso, em uma tarde de debates entre escolas por microrregião, desenvolvendo o aprofundamento conceitual sobre os textos dos palestrantes; um terceiro, em horário de JEl (Jornada Educacional Integrada) de cada escola, coordenado pelos próprios professores participantes, no qual estes se tornam multiplicadores do debate do curso a partir da projeção dos vídeos temáticos e do debate dos textos da apostila para outros professores de sua unidade escolar que não puderam se inscrever no curso; e um quarto encontro, bastante inovador, coordenado pelos monitores, mas realizado em cada escola participante em um horário de JEl estabelecido pelo grupo de professores inscritos e voltado à discussão de práticas e questões específicas de cada unidade escolar.

Em resumo, essa última versão do curso em Direitos Humanos, Cidadania e Educação tornou-se um amplo trabalho de aperfeiçoamento docente de oito meses, a um tempo conceitual, prático e presente no cotidiano escolar de 37 unidades escolares inscritas. No total, a programação contou com oito palestras

6. Os professores responsáveis pelas palestras relativas aos temas indicados foram, respectivamente: Dalmo de Abreu Dallari (Faculdade de Direito-USP), José Sérgio Carvalho (Feusp), Oscar Vilhena Vieira (Faculdade de Direito-PUC-SP), Flávia Schilling (Feusp), Isabel Galvão (Feusp), Victor Paro (Feusp) e Eugênio Bucci (Faculdade de Jornalismo da Fundação Cásper Líbero). 
mensais, ${ }^{7}$ oito encontros por microrregião do NAE 10 e oito encontros por escola, realizados em espaços de JEl. O objetivo dessa última modalidade de encontros, a maior inovação desse curso, é o de ajudar as escolas a viabilizar seus programas de vinculação do processo educativo aos ideais da cidadania e dos direitos humanos, tanto pela inclusão temática como, sobretudo, pela adoção de práticas que reflitam os compromissos da escola com os ideais de uma sociedade democrática.

Nesse sentido, a tarefa dos monitores tornou-se dupla: inicialmente a eles cabe o aprofundamento das discussões conceituais e sua aproximação com a perspectiva escolar; já nos encontros por escola, sua função tem sido a de coordenar os esforços dos professores a fim de viabilizar suas propostas. A eles não coube, portanto, a proposição de trabalhos unificados, mas antes a criação de uma cultura de debates e planejamento conjunto de meios para que as escolas proponham soluções específicas para suas condições.

Em relação ao grupo de monitores, cabe destacar que esse foi formado, de acordo com a proposta conjunta, tanto por membros da equipe do Projeto Direitos Humanos nas Escolas como por membros da equipe pedagógica do NAE - em um total de vinte monitores, dez do Projeto e dez do NAE. A formação desses monitores se fez conjuntamente para além de um encontro mensal de acompanhamento dos trabalhos: todos participaram do curso Introdução aos Estudos da Educação - ministrado pelo professor doutor José Sérgio CarvaIho, coordenador do projeto -, cuja temática incide exatamente sobre as questões abordadas.

\section{Conclusão}

A partir das experiências anteriores, das avaliações parciais de 2003 e do planejamento para 2004, o Projeto Direitos Humanos nas Escolas, pretende dar continuidade aos cursos de formação de professores, introduzindo, contudo, uma novidade importante: a inserção de atividades culturais (como apresentação de filmes, pe- ças de teatro, leituras de obras literárias, etc.) que possam desencadear a temática a ser analisada. Acreditamos que esse tipo de procedimento pode, a um só tempo, tornar mais concretas discussões complexas do ponto de vista conceitual, como as que, entre outras, dizem respeito à violência social, à democracia e ao racismo, aproximando-as da realidade vivida pelos professores e aumentando-lhes seu repertório cultural. Elas podem ainda sugerir formas de vinculação entre a temática, as diversas expressões culturais e as práticas docentes passiveis de extensão para a própria experiência docente das escolas. Assim, em síntese, a proposta dos cursos deverá ter como objetivo:

- Congregar professores de uma mesma unidade de ensino, por meio de inscrições por equipe, a fim de aumentar a possibilidade de mudanças institucionais, raras quando o objeto da ação é um professor isolado de seus pares.

- Transformar a prática corrente de palestras isoladas em um Curso de Extensão Cultural, certificado pela USP, de forma a articular e aprofundar as temáticas e colaborar na progressão da carreira dos docentes inscritos.

- Criar grupos de discussão para debate, com uma média de vinte participantes, a fim de promover aprofundamento das concepções veiculadas nas palestras.

- Criar mecanismos de atuação direta nas escolas, por intermédio da participação nas JEls (reuniões pedagógicas semanais), a fim de fomentar a reflexão sobre as práticas correntes e a proposição de inovações vinculadas aos ideais propostos.

- Ampliar o repertório cultural dos professores, por meio da apresentação e discussão de obras literárias, cinematográficas, musicais e acadêmicas.

- Fomentar a presença de eventos e obras cul-

7. Nessa última versão, além de permanecerem os temas e palestrantes anteriormente envolvidos no curso para diretores do NAE 10, contamos com as seguintes participações: Maria Victória Benevides Soares (Feusp), Terezinha de Azerêdo Rios (Faculdade de Pedagogia da PUC-SP), Maria Rita Kehl (Faculdade de Psicologia da PUC-SP), Heloísa Buarque de Almeida (Antropologia Unicamp, CEM/Cebrap), Luíza Cristina Friescheizen (Ministério Público Federal), Célia Giglio (Diretora da Escola Estadual Filomena Matarazzo). 
turais no currículo escolar, ligando a temática da democracia e dos direitos humanos ao cotidiano escolar.

- Criar mecanismos que garantam a presença dos coordenadores pedagógicos no acompanhamento das atividades do curso, aproximando os ideais nele veiculados aos projetos político-pedagógicos das unidades participantes.

- Propiciar o envolvimento e a formação das equipes pedagógicas das coordenadorias de ensino participantes, a fim de criarmos uma parceria entre a universidade pública e a rede municipal de ensino.

- Levar os professores a buscarem soluções locais a partir de um conjunto de valores comuns e vinculados aos princípios legais e públicos que devem reger as atuações das instituições escolares.

\section{Referências bibliográficas}

AZANHA, J. M. Educação: alguns escritos. São Paulo: Cia Editora Nacional, 1987.

BRASIL. Secretaria de Educação Fundamental. Parâmetros Curriculares Nacionais, Brasília: MEC/SEF, 1998 (v. Temas Transversais).

CARVALHO, J. S. Podem a ética e a cidadania se ensinadas? Pro-Posições: Revista da Faculdade de Educação, Campinas, v. 13, n. 3, p. 39, 2002.

SÃO PAULO. Conselho Estadual de Educação. Indicação e Deliberação 07 e 08, 2000.

SCHEFFLER, I. A linguagem da educação. São Paulo: Edusp/Saraiva, 1978.

VIEIRA, 0. V. Moralidade pessoal e ética pública. In: CARVALHO, J. S. (Org.) Educação, cidadania e direitos humanos. Petrópolis: Vozes, 2004.

Recebido em 24.11 .03

Aprovado em 12.03.04

José Sérgio Carvalho é mestre e doutor em Filosofia da Educação pela USP, onde leciona nos programas de graduação e pós-graduação da Faculdade de Educação. É coordenador geral do Projeto Direitos Humanos nas Escolas.

Adriana Pereira Sesti é bacharel licenciada em Geografia pela USP, e professora de Geografia do ensino fundamental II da Escola Municipal Professora Eda Teresinha Chica Medeiros e membro do Projeto Direitos Humanos nas Escolas.

Julia Pinheiro Andrade é bacharel licenciada em Geografia pela USP e professora de Geografia do ensino fundamental II do Colégio Ítaca e membro do Projeto Direitos Humanos nas Escolas.

Luciano da Silva Santos é bacharel licenciado em História pela USP e membro do Projeto Direitos Humanos nas Escolas.

Wellington Tibério é bacharel licenciado em Geografia pela USP e membro do Projeto Direitos Humanos nas Escolas. 